\title{
Prevalence of Bovine Trypanosomosis in Didessa Woreda, Oromiya Region, Ethiopia
}

\author{
Netsa Bekele ${ }^{1}$, Abriham Kebede ${ }^{2^{*}}$ and Endalu Mulatu ${ }^{3}$ \\ ${ }^{1}$ College of Veterinary Medicine, Mekelle University, Mekelle, Ethiopia \\ ${ }^{2}$ School of Veterinary Medicine, College of Medical and Health Science, Wollega University, Ethiopia \\ ${ }^{3}$ College of Agriculture, Metu University, Bedelle, Ethiopia
}

*Corresponding author: Abriham Kebede, School of Veterinary Medicine, College of Medical and Health Science, Wollega University, PO Box: 395, Ethiopia, Tel: +251-917-095-077; E-mail: abrahamkebede2016@gmail.com

Rec date: November 22, 2017; Acc date: January 05, 2018; Pub date: January 06, 2018

Copyright: (c) 2018 Bekele N, et al. This is an open-access article distributed under the terms of the Creative Commons Attribution License, which permits unrestricted use, distribution, and reproduction in any medium, provided the original author and source are credited.

\begin{abstract}
A cross sectional study was conducted at Didessa Woreda, Oromiya region, south west Ethiopia. The study was carried out from November, 2011 to April 2012 on indigenous cattle breed managed under mixed corop-livestok production system, to determine the prevalence of bovine trypanosomosis. This study employs parasitological survey by the use of Buffy coat examination, thin smear and hematological study. The overall prevalence of bovine trypanosomosis in the present study was $5.47 \%$. The predominant species recovered was Trypanosome congolense $(61.9 \%)$ followed by Trypanosome vivax (23.8\%) the Trypanasome brucei $(9.5 \%)$. Mixed infection due to Trypanosome congolense and Trypanosome vivax (4.7\%) was also recorded in the study. Discrepancy in the prevalence of Trypanosome infection was recorded in the different age groups, between sex and different body conditioned animals, but the difference was not statically siginificant $(p>0.05)$. The mean PCV of parasitemic animals was significantly lower $(21.15=4.675)$ than the parasitemic animals $(24.316=4.93)(p<0.05)$. Although the present study came up with low prevalence of bovine trypanosomiasis in the stydy area, the potential impact of this disease on production and productivity of cattle shall not undermined. Therefore, sustainable community based tsetse and trypanosomsis control program should be implemented.
\end{abstract}

Keywords: Didessa; Ethiopia; Prevalence; Trypanosomiasis

\section{Introduction}

Trypanosomosis is disease cussed by unicellular parasites (trypanosome) found blood and other tissue of vertebrates; including live stock, wild life and people [1]. It is a serious disease in domestic live stock causing a significant negative impact on food production and economic growth in many parts of the world, particularly in subsaharan Africa [1-3]. Its epidemiology and impact on live stock production are largely determined by the prevalence, and distribution of the disease and its vectors in the affected area [4].

This disease is transmitted mainly by tsetse flies (cyclically), biting flies (mechanically) and by other means of transmission [3,5]. The most important species that infected cattle include Trypanosome congolense. T. brucei and T. vivax. Mechanically transmission is particularly important in relation to $T$. vivax and $T$. evansi particularly on the fringe of tsetse areas. It can occur in the presence of biting files of genus Tabanus. Haematopia, chrysopas and stomaxys [6].

Tsetse flies ingest Trypanosome in blood or lymph node while feeding on the host. The Trypanosome undergoes a cycle of development and multiplication in digestive tract of the fly until the infective metacyclic trypanosomes (metatrypanosome) are produced [3]. They undergo a transformation losing their typical Trypanosome or trypomastogote and metacyclic Traypanosomes which are infective froms of the host [7]. African trypanosomes lose infectivity for mammals when they enter the tsetse fly gut and must complete their development cycle with differentiation to the metacyclic stage before infective parasites can be transmitted in the tsetse saliva [8].
Approximately $30 \%$ of the total cattle population in African continent and about 50 million people are exposed to animal trypanosomosis and human sleep sickness respectively [9].

Tsetse flies (Glosina) inhabit wide range of habitats covering over 10 million $\mathrm{km}^{2}$ representing $37 \%$ of the African continent and affecting 37 countries including Ethiopia [10]. In Ethiopia tsetse flies are confined to the southern and western regions. Between the longitude 330 and $380 \mathrm{E}$ and latitude 50 and $120 \mathrm{~N}$. tsetse fly infested areas lies in the low land of and also in the river valley of Abay (Blue Nile), Baro, Akobo, Ghibe, Didessa and Omo [11]. Currently about $220,000 \mathrm{~km}^{2}$ area is infested with tsetse flies normally Glossina fuscipes, Glossina tachnoides, Glossina pallidipes, Glossina marsitans, Glossina Longipennis [12]. About 15-20 percent of the low land believed to be suitable for livestock production by one or two species of the tsetse flies [13].

Bovine trypanosomosis is a serious constraint to agricultural production in extensive tsetse infested areas of Ethiopia low land [14]. Trypanosomosis is prevalent in two main regions of Ethiopia i.e., the North West and the south west regions [6]. In Ethiopia, Trypanosomosis is one the most important disease limiting live stock productivity and agricultural development due to its high prevalence in the most arable and fertile land of south west part of the country following the grater basins of Abay, Omo, Ghibe, Didessa and Baroo with a high potential for agriculture [12].

The most important Trypanosome species affecting live stock in Ethiopia are T. congolense, T. vivax, T. brucei, in cattle, sheep and gaot, T. evansi in camel, and T. equiperdum in horse [6]. In Giemsa stained blood smears the species are distinguished by their size, shape, 
location, the size of kinetoplast, position of nucleus and the attachment and length of flagellum. Trypanosomes move actively and progress by movement of the undulating membrane and the free flagellum when present [3]. Trypanosomes are characteristically leaf like in shape; they are a single flagellum and attached to the organism by undulating membrane [15].

Animal caused by trypanosomosis is manifested anemia, generalized enlargement of superficial glands, loss of body condition, fever, and loss of appetite [7]. In recent years a number of drugs effective against cattle trypanosomosis have been introduced for both curative and prophylactic use $[5,15]$. Curative treatment is the most effective in herds that are inspected at regular intervals [3]. Control and strategies in the trypanosomosis concentrate on vector control, parasites control with chemotherapy and chemoprophylaxis and use their inherent trypano tolerant in some breeds of animals [6].

The economic burden of trypanosomosis is not only due to the direct losses resulting from mortality, morbidity and infertility of the infected animals but also it is due to the indirect losses like exclusion of live stock and animal; power based crop production from the huge fertile tsetse infested areas [16]. In Ethiopia about 5.5 million heads of cattle are exposed to the risk of trypanosomosis. This disease reduces meat and milk production of animals recovering from it. In addition to this some drugs are costly to treat animals that are diseased. Despite bovine trypanosomosis, have impacts on cattle production and prevalence of the disease in the study area.

Therefore the objective of this research was:

- To estimate the prevalence of bovine trypanosomosis in Didessa Woreda.

- To determine the species of trypanosomes that affect bovine species in study area.

- Determining PCV values in parasitemic and non-parasitemic animals.

\section{Materials and Methods}

A number of materials were required for both study of the disease and writing of this thesis. The list of the materials were sides, cover slips, PCV reader, pippet or stick, Bunsen burner, haematocrit clay, haematocrit centrifuge, microscope and equipment used for blood collection, (needle, needle holder, test tubes and haematocrit tube, the reagent used for laboratory test like iodine, methyl alcohol, giemsa stain, methyl blue stain and others.

\section{Study area}

The study area was located in oromia region, Illu Ababor Zone at Didessa woreda. Dembi is the administrative center of Didessa district. This district is bordered by Gechi Borecha distirict in north, Limmu Korsa in east, Sattama in west and Gumay in south and found at south west of Ethiopia at the distance of about $420 \mathrm{~km}$ from Addis Ababa. The topography of this district is characterized by plateaus of central and western plains of Didessa valley. The main river for this district is Didessa River and the tributaries Mulade, Asha and Dibo. Didessa is the smallest district in Ilu Ababor Zone with area of $615 \mathrm{~km}^{2}$. The elevation varies in this area from 1360-2340 meter above sea level. The annual mean temperature for most part of the district is $13^{\circ} \mathrm{C}-28^{\circ} \mathrm{C}$ and annual rain fall is about $900-1000 \mathrm{~mm}$. the climatic condition of the area includes: Dega, woina Dega and kola cover $16 \%, 64 \%$, and $20 \%$ of the district respectively. The lands used for cultivation are cultivated land 4719.57 hectar, grazing and 9848.45 hectare, forest 10682.7 hectare and the other 724 hectare [17].

\section{Study population}

Bovine with any age and either sex in Dinge Beraha and Busi Settkement area were selected for the collection of samples. There are a total number of 21,867 bovine species which is greater in number than other species of animals in that area [17]. A total of 384 cattle were selected with 192 from each peasant association. The cattle selected for sample collection were indigenous zebu cattle in Ethiopia.

\section{Study design}

A cross sectional type of study was conducted to determine the current prevalence of bovine trypanosomosis in the study area. The selected cattle were categorized according to their body condition (good, medium and poor), sex (female and male) and age (<year, 2-3 year and $>3$ ).

\section{Sample size and sampling method}

The simple random sampling technique was applied to collect from the ear vein. The sample size can be determined based on the study type and sampling method for investigation, 95\% confidence interval, $5 \%$ desired absolute precision and $50 \%$ average prevalence and 38.4 cattle were sampled by the following formula [18].

$$
\begin{aligned}
& \mathrm{N}=(1.96)^{2} \mathrm{P}_{\exp }\left(1-\mathrm{P}_{\exp }\right) / \mathrm{D}^{2} \\
& \text { Where } \mathrm{n}=\text { required sample size } \\
& \mathrm{P}_{\exp }=\text { expected prevalence } \\
& \mathrm{D}^{2}=\text { desired absolute precision }
\end{aligned}
$$

\section{Study methodology}

Buffy coat technique: A small blood was collected from an ear vein using heparinized microhaematocrit capillary tube. A haematocrit tube with a whole blood sample and end was sealed with haematocrit clay. The tube was centrifuged at 12000 revolutions per minute for five minutes. After centrifugation Trypanosome were usually found in or just above the buffy coat layer. The capillary tube was cut using a diamond tipped pen $1 \mathrm{~mm}$ bellow the Buffy coat to include the upper most layers of the red blood cells and $3 \mathrm{~mm}$ above to include the plasma. The content of capillary tube was expressed on to side, homogenized on to clean side and covered with cover slip. The slide was under $\mathrm{x} 40$ objective $\mathrm{x} 10$ eye piece for the movement of the parasites [19].

Thin blood smear: Blood drop of blood from a micro haematocrit capillary tube the side applied to clean side and spread by using another clean side at angle of 450, air dried and fixed for 2 minutes in methyl alchohol, then immersed in Giemsa stain (1:10 solution) for 50 minutes [20] drained and washed of excess stain using distilled water, allowed to dry by standing up right on the rock and was examined under microscope with oil immersion objective lens. In Giemsa stained smears the species were distinguished by their size, shape, location and size of the kinetoplast, position.

Measuring of packed cell volume: Blood samples were obtained by puncturing marginal car vein with lancet and collected directly in to a capillary tube. The capillary tubes were placed in micro haematocrit centrifuge with sealed end outer most. The tube was loaded 
Page 3 of 5

symmetrically to ensuring good balance after screwing the rotators cover and closing the centrifuge lid, the specimens were allowed to centrifuge at 12,000 revolutions per minute for 5 minutes. Tubes were then placed in a haematocrit and readings were expressed as a percentage of packed cells to the total volume of whole blood. Animals with $\mathrm{PCV}<24 \%$ were considered to be anemic.

Body condition scoring: The body condition was characterized good, medium and poor according to Nicholson and Butter worth [21].

Data management and analysis: Row data individual animals and parasitological examination were inserted in to micro soft excel spread sheets to create a data base and transferred to SPSS version 17.0 software program for data analysis.

\section{Results}

Out of the total 364 cattle examined 21(5.47\%) cattle were positive for trypanosomosis, the prevalence of trypanosomosis were not statistically siginificant $(\mathrm{P}>0.05)$ between different sex $(\mathrm{P}=0.611)$, age $(\mathrm{p}=0.676)$ or body condition score $(\mathrm{p}=0.4)$ of the animals as indicated in Tables 1-3 respectively. From the total infected animals 13 (61.9\%), 5 (23.8\%), 2(9.5\%) and $1(4.76 \%)$ were infected with $T$. congolense, $T$. vivax and with mixed infection of $T$. congolense and $T$. vivax respectively (Table 4 ).

\begin{tabular}{|l|l|l|l|l|l|}
\hline Sex & Frequency & Percent & $\begin{array}{l}\text { Trypanosome } \\
\text { infected }\end{array}$ & $\begin{array}{l}\text { Rate of } \\
\text { infection } \\
\text { (\%) }\end{array}$ & $\begin{array}{l}\text { P- } \\
\text { value }\end{array}$ \\
\hline Female & 203 & 52.9 & 10 & 4.9 & 0.611 \\
\hline Male & 181 & 47.1 & 11 & 6.07 & \\
\hline Total & 384 & 100 & 21 & & \\
\hline
\end{tabular}

Table 1: Prevalence of bovine Trypanosome with sex in Didessa woreda.

\begin{tabular}{|c|c|c|c|c|c|}
\hline Age & Frequency & Percent & $\begin{array}{l}\text { Trypanosome } \\
\text { infected }\end{array}$ & Prevalence & $\begin{array}{l}P \\
\text { value }\end{array}$ \\
\hline$(<1)$ & 8 & 2.1 & 0 & 0 & \\
\hline$(2-3)$ & 92 & 24 & 5 & 5.43 & 0.67 \\
\hline$>3$ & 284 & 74 & 16 & 5.63 & \\
\hline Total & 384 & 100 & 21 & & \\
\hline
\end{tabular}

Table 2: Prevalence of bovine Trypanosome with age in Didessa woreda.

\begin{tabular}{|l|l|l|l|l|}
\hline Body score & Frequency & $\begin{array}{l}\text { Numbers of } \\
\text { animal infected } \\
\text { with trypanosome }\end{array}$ & Prevalence & P-value \\
\hline Good & 69 & 3 & $3(4.30$ & 0.04 \\
\hline Medium & 150 & 6 & $6(4)$ & \\
\hline Poor & 165 & 12 & $12(7.27)$ & \\
\hline
\end{tabular}

Table 3: Prevalence of bovine Trypanosome with Body condition in Didessa woreda.

\begin{tabular}{|l|l|l|l|}
\hline Species & Total & Frequency & Percent \\
\hline T. brucei & 21 & 2 & 9.52 \\
\hline T. congolense & 21 & 13 & 61.9 \\
\hline T. vivax & 21 & 5 & 23.8 \\
\hline $\begin{array}{l}\text { Mixed (T. congolense } \\
\text { and T. vivax) }\end{array}$ & 21 & 1 & 4.76 \\
\hline
\end{tabular}

Table 4: Prevalence of bovine Trypanosome species in Didessa woreda.

The mean PCV of the animals infected with trypanosomes $(21.857$ $\neq 4.67)$ was significantly lower $(\mathrm{p}<0.032)$ than the average PCV of the animals that were parasitologically negative was $(24.316 \neq 4.93)$ (Table $5)$.

\begin{tabular}{|c|c|c|c|c|c|}
\hline Condition & $\begin{array}{l}\text { No. } \\
\text { Examined }\end{array}$ & $(\mathrm{PCV}<25 \%)$ & $(P C V>25 \%)$ & $\begin{array}{l}\text { Mean pcv } \\
\%+\text { sd }\end{array}$ & $\begin{array}{l}p- \\
\text { value }\end{array}$ \\
\hline Parasitemic & $21(5.47 \%)$ & $17(80.95 \%)$ & $4(19.05 \%)$ & $\begin{array}{l}21.857 \neq \\
4.675\end{array}$ & 0.03 \\
\hline Aparasitmeic & $\begin{array}{l}363 \\
(84.5 \%)\end{array}$ & $\begin{array}{l}173 \\
(47.66 \%)\end{array}$ & $\begin{array}{l}190 \\
(52.34 \%)\end{array}$ & $\begin{array}{l}24.316 \neq \\
4.93\end{array}$ & \\
\hline Total & 384 & $\begin{array}{l}190 \\
(49.48 \%)\end{array}$ & $\begin{array}{l}194 \\
(50.52 \%)\end{array}$ & & \\
\hline
\end{tabular}

Table 5: Mean packed cell volume and standard deviation of infected and non-infected animal cattle in Didessa woreda.

\section{Discussion}

The result of the present study revealed an overall trypanosomosis of $5.45 \%$. This finding was lower than the previously reported prevalence rate of $23 \%$ in western Ethiopia, $21 \%$ in Metekal district, $18.5 \%$ in Arba-minchi district, $17.5 \%$ in upper Dideesa valley areas, and $11.7 \%$ in Abay Basin north western Ethiopia of tsetse infested regions [22-26]. The lower prevalence in the current study might due to the low sensitivity of the parasitological diagnostic method, the uncontrolled use of trypanocidal drugs, application of relatively well designed method of tsetse control and treatment, expansion of cultivation in the area which in directly affects flies distribution and awareness of the people towards the control and treatment of the disease were improved. Even though, the data was not collected during rainy season, [27] revealed that there is significantly high infection rate following the months with high rain due the emergency of biting flies $t$ high rate. This implies that the low prevalence of trypnosomosis in this study may be related with decrease in fly population during dry season.

The finding of this revealed that the majority of the infection was due to $T$. congolense $(61.9 \%)$ followed by $T$. vivax $(23.8 \%)$ and $T$. bruecei (9.5\%). Mixed infection of T. congolense and T. vivax was also prevalent $(4.76 \%)$. The higher proportion of $T$. cogolense infection study area was in agreement with Trypanosome species prevalence data from other tsetse infested regions of Ethiopia, where the $T$. congolense is the most prevalent species in cattle [28]. The ratio of $T$. congolense, $T$. vivax and $T$. brucei was 2.6: 1:0.4 indicating high Trypanosome infection due to T. conogolense. The percentage specious distribution in our finding was similar to Nigatu his co-workers finding in Abay Basin (T. congolense (66.1\%) followed by $T$. vivax (20.8\%) [24]. The predominant species of $T$. congolense compared to $T$. 
vivax and the development of better immune response to $T$. vivax infected animals $[29,30]$.

The prevalence of infection between sex categories was $6.07 \%$ in male and $4.9 \%$ in female animals. However, there was no significance difference between sex groups $(\mathrm{p}=0.611)$.

There no significance difference observed in age groups in the study groups in the study period but relatively higher rates observed in adult ( $>3$ years) animals when compared to young animals. This may due to exposition adult animals for the tsetse fly [31]. When they are freely grazing and also may be due to immune suppression as a result of stress factors such as lactation and when they are travelling along distance through tsetse challenges are for drafting purpose in males. The low prevalence in young animals may also be due to the natural protection to some extent by maternal antibodies [32].

Although higher infection rate was observed in poor body conditioned animals as compared to good and medium, in the present study no statistically different was observed this groups $(p=0.4)$. Similar results were reported from Tselemty woreda, Western Tigtay, Northern Ethiopia [33]. PCV is the most reliable indicator of anemia in trypanosomosis [34,35]. In our study Trypanosome infection results in a significant decline in PCV, this is in agreement with previous finding that are reported by different authors at different time [36,37].

The mean PCV values of studied animals was significantly $(\mathrm{p}<0.05)$ varying between parasitemic $(21.857 \neq 4.857 \%)$ and a parasitaemic $(24.316 \neq 4.93 \%)$. This result was in agreement with the previous result by Sinishaw et al. [27]. The appearance of parasitologically negative animals with PCV values of less than the threshold values (25\%) may be due to the inadequacy of detection method used or delayed recovery of anemic situation after current treatment with trypanocidal drugs; and the occurrence of positive animals with PCV of greater than $25 \%$ might it be thought of recent infection. Trypanosome infection and mean values obtained in this study in the parasitaemic animals was found to be highly associated. Similar results were also reported by different authors in southern, north western and south western Ethiopia $[24,30,38]$. It was generally accepted that the mean PCV in affected by many factors (helmenthiasis, tick born disease and Nutritional imbalance) other than trypanosomosis. However, these factors are likely to affect both trypanosomosis positive and negative animals [39].

\section{Conclusion and Recommendation}

The overall prevalence of bovine Trypanosome infection is study area was lower than the previous report but it is important disease that affects the health as well as productivity of cattle in Didessa district. There was no statically significant difference between sex, ages, and body condition. The mean PCV of parasitemic animals due to $T$. Congolese, T. vivax, and T. brucei and mixed was significantly lower than a parasitemic animal.

Although, the present study low prevalence of bovine trypanosomosis in the study area potential impact of $T$. congolense, $T$. vivax, T. burucei infection on production and productivity of cattle shall not be undermined. Based above conclusion the following recommendations are recommended:

- Sustainable community based tsetse and trypanosomosis control program should be implemented.
- Major concern should be given to the identification of trypanosomes species with the highest prevalence and control measure should be targeted accordingly.

- Training and advising the society how to control the vector of the disease should be practiced.

- Use of the trypano-tolerant breeds of animals in the highly prevalent area should also be recommended.

\section{Competing Interest}

The authors declare that they have no competing interest.

\section{Acknowledgement}

We would also like to express our gratitude to Jigjiga University and people of Didessa district for supporting us to conduct this research.

\section{References}

1. Tesfaye M (2002) Report of Trypanosome Infection Rate in Morsitans GM and Tachninoides G In Didessa Valley.

2. Taylor KA (1998) Immune Response of Cattle to African Trypanosomes: Protective or Pathogenic. Int J Parasitol 28: 219-240.

3. Uilenberg G (1998) A field Guide for Diagnosis, Treatment And Prevention of African Animal Trypanosomosis. IN FAO. Adopted from the Original Edition. Rome, pp: 43-138.

4. PATTEC (2001) Pan African Tsetse and Trypanosomosis Eradication Campaign. PATTEC plan of action, pp: 28-37.

5. Nuru A (1993) Prevalence Rate of Bovine Trypanosomosis in Tsetse Protected and Unprotected Areas of Upper Valley.

6. Abebe G (2005) Trypanosomosis In Ethiopia. J Biol Sci 4: 75-121.

7. Urquhart GM, Armour J, Duncan JI, Dunn AM, Jennings FW (1992) Veterinary Parasitology. 3rd (edn.) Oxford, Blackwell Science.

8. Wright G (1989) In: Vetrinary Parasitology and Haemoparasite Vaccines. Florida 132-147

9. WHO (2006) Trypanosomosis in Ethiopia.

10. Finelle P (1980) Program for Control of African Trypanosomosis and Related Development. Isotope and Radiation Research on Animal Disease and Their Vectors, pp: 3-14.

11. Langridge AP (1976) Tsetse and Trypanosomosis survey of Ethiopia. Ministry of Overseas department.

12. MOA (1995) Federal Democratic Republic of Ethiopia, Ministry of livestock and Fisheries.

13. NTTICC (2002) Annual report. Bedelle.

14. Slingenbergh J (1992) Tsetse Control and Agricultural Development in Ethiopia. World Anim Rev 70: 30-36.

15. Soulsyby JEL (1982) Helminths, Arthropods and Protozoa of Domesticated Animals. 7th (edn.), Bailliere Tindall, London.

16. Mariam AK (2000) Study of Trypanosomosis and its Vectors in Humbo and Merab Woredas. J Eth Vet Assoc 4: 61-77.

17. Wereda D (2011) Didessa Woreda profile.

18. Thrusfield M (2005) Veterinary Epidemology. 2nd (edn.) Blackwell Series, pp: 233-250.

19. Paris J, Mcodimba F (1982) A Comparative Evaluation of the Parasitological Technique Currently Available for the Diagnosis of African Trypanosomosis in Cattle. Acta Tropica 39: 1-11.

20. Cherinet TAG, San S, Panasam JM, Bossche PVD (2005) A longitudinal Study of Bovine Trypanosomosis In Tsetse Free and Tsetse Infested Zone of Amhara Region, North West of Ethiopia. EVA 6374.

21. Nocholson MJ (1986) A guide to Condition Scoring of Zebu Cattle. ILCA, Addis Ababa.

22. Bitew M, Amrdie Y, And A, Tolosa T (2011) Prevalence of Bovine Trypanosomosis in Selected Areas of Jabi Tehenan District, West Gojam 
Citation: Bekele N, Kebede A, Mulatu E (2018) Prevalence of Bovine Trypanosomosis in Didessa Woreda, Oromiya Region, Ethiopia. J Vet Sci Technol 9: 503. doi:10.4172/2157-7579.1000503

Page 5 of 5

of Amhara Regional State, North Western Ethiopia. Afr J Agri Res 6 140-141.

23. Muturi K (1999) Epidemiology of Bovine Trypanosomosis in Selected Sites of the Southern Rift Valley of Ethiopia.

24. Nigatu SD (2004) Epidemiology of Bovine Trypanosomosis in The Abbay Basin Areas of North West Ethiopia. Revue d'élevage et de médecine vétérinaire des pays tropicaux 58: 3 .

25. Terzu D (2004) Seasonal Dynamics of Tsetse and Trypanosomosis in Selected Sites of Southern Nations Nationalities and Peoples Regional State, Ethiopia. Eth Vet J 12: 77-92.

26. Towolde N, Abebe G, Eilser M, Dermott M, Grierner J, et al. (2004) Application of Field Methods to Assess Isometamidium Resistance of Trypanosome in Cattle in Western Ethiopia. Acta Trop 90: 163-170.

27. Sinishaw A, Abebe G, And MD, Yoni W (2006) Biting Flies and Trypanosoma vivax infection in three highland districts bordering lake Tana, Ethiopia. Vet Parasitol 142: 35-46.

28. Abebe G, Jobre Y (1996) Trypanosomosis: A Threat to Cattle Production in Ethiopia. Revue De Med Vet 147: 897-902.

29. Maclennan KJR (1980) Tsetse Transmitted Trypanosomosis In Relation to the Rural Economy in Africa. Wild Anim Rev 36: 2-22.

30. Rowlands GJ, Authei ED, Leak SGA (1993) Epidemiology of Bovine Trypanosomosis in the Ghibe Valley South West Ethiopia. Factors Associated with Variations in Trypanosome Prevalence, Incidence of New Infections and Prevalence of Recurrent Infections. Acta Trop 53: 135-150.
31. Fines R (1970) Pathogenesis and Pathology of Animal Trypanosomiasis. In: Mulligan HW (ed.) The African trypanosomiases, pp: 729-750.

32. Fimmen HO, Horchiners F (1999) Clostral Antibodies and Trypanosome congolese Infection in Calves. Trypanotolerance Research and Application 116: 173-178.

33. Abebayehu T, Ehadgu B, Mekibeb R, Mekuria S (2011) Mechanically Transmitted Bovine Trypanosomosis In Tselemty Wereda, Western Tigray, Northern Ethiopia. Agric J 6: 10-13.

34. Morrison WL (1981) Bovine Trypsnosomosis. In: Ristic Mand Mclntyre, 1st (edn.) Pp: 486-488.

35. Murray M (1978) Anemia of Bovine African Trypanosomiasis: An overview. In Pathogenicity of trypanosomes: proceedings of a workshop, IDRC, Ottawa, ON, CA, pp: 121-127.

36. Losos GJ, Keda B (1972) Review of the in Domestic and Laboratory Animals Caused by T. Congolense, T. Brucei, T. rhodensi and T. gambiense. Vet Pathol 9: 1-23.

37. Obi VAT (1980) Hematological Study on Domestic Animals in Nigeria: The Effect of Age, Breed and Hemoglobin Type in Bovine Hematologyand Anemia. Zbi Vet Med 27: 773-778.

38. Bekele J (2004) Control of Tsetse and Trypanosomiasis in Southern Rift Valley of Ethiopia.

39. Bossche PV, Rowlands GJ (2001) The Relationship between the Parastological Prevalence of Trypanosomal Infaction in Cattle and Herd Average Packed Cell Volume. Acta Tropic 78: 163-170. 